\title{
PROGRESIVISME DAN PERSPEKTIFNYA TERHADAP PEMBELAJARAN DI ERA PANDEMI COVID-19
}

\author{
Hasna Ulayya Eliana'),Rino Richardo²), Rima Aksen Cahdriyana ${ }^{\text {3) }}$ \\ 1)Universitas Alma Ata, Jalan Brawijaya No.99 Yogyakarta, Bantul; elianahasna5@gmail.com \\ 2)Universitas Alma Ata, Jalan Brawijaya No. 99 Yogyakarta, Bantul; rinorichardo@almaata.ac.id \\ ${ }^{3)}$ Universitas Ahmad Dahlan, Jl. Ringroad Selatan, Kragilan, Tamanan, Kec. Banguntapan, Bantul, \\ Daerah Istimewa Yogyakarta, Bantul; rima.cahdriyana@pmat.uad.ac.id
}

\begin{abstract}
Abstrak. Tujuan penelitian untuk mendeskripsikan dan menjelaskan konsep filsafat progresivisme, perspektif progresivisme terhadap pembelajaran di era pandemi covid-19, serta pandangan progresivisme terhadap belajar, pendidik dan peserta didik,. Penelitian ini berupa studi kepustakaan (library research). Data yang digunakan adalah data sekunder yang bersumber dari buku dan jurnal ilmiah elektronik. Analisis data dalam penelitian ini menggunakan metode analisis isi. Hasil kajian dalam studi ini menunjukkan bahwa progresivisme sebagai filsafat pendidikan berperan dalam memberikan dasar pijakan dalam mengembangkan sistem pembelajaran yang fleksibel serta menyesuaikan dengan kemajuan dan perkembangan ilmu pengetahuan dan teknologi terutama dalam masa pandemi covid-19.
\end{abstract}

Kata Kunci : Progresivisme, Pandemi, Covid-19, Pembelajaran

\section{PROGRESSIVISM AND THE PERSPECTIVES ON LEARNING PROCESS, IN THE ERA OF COVID-19 PANDEMIC}

\begin{abstract}
This research aims to find and describe the philosophy concept of progressivism and the persepctive toward the learning process in the era of Covid19 pandemic, as well as the perspective toward learning, educators and students. This research is a library research using books and electronic scientific articles as data sources. In collecting the data, researchers browse online data through the Google scholar database. While the data analysis applied in this study is the content analysis method. The research results show that progressivism as an educational philosophy plays an important role in providing a basis for developing a flexible learning system adapting to the progress and development of science and technology, especially during the Covid-19 pandemic.
\end{abstract}

Keyword : Progressivism, Pandemic, Covid-19, Learning Process

\section{Pendahuluan}

Wabah covid-19 yang telah dinyatakan sebagai pandemi oleh badan World Health Organization (WHO) telah memberikan banyak dampak diberbagai sektor kehidupan manusia. Salah satu yang terdampak adalah sektor pendidikan (Sumantyo, 2020). Proses pembelajaran yang pada umumnya dilaksanakan di sekolah, adanya interaksi secara langsung antara pendidik dan peserta didik atau antar peserta didik berubah menjadi 
pembelajaran dalam jaringan (daring). Dengan kata lain, kegiatan pembelajaran tidak lagi dilaksanakan di sekolah, melainkan di rumah masing-masing menggunakan aplikasi online sebagai medianya.

Pembelajaran online dengan berbagai aplikasi yang sudah ada saat ini dan masih akan terus berinovasi sebagai hasil pengembangan ilmu pengetahuan dan teknologi sebagai solusi untuk menghadapi berbagai bentuk masalah dalam kehidupan manusia, sebagaimana masalah wabah covid-19 yang memberikan dampak terhadap pembelajaran. Pembelajaran online merupakan salah satu solusi yang belum tergantikan dimasa pandemi saat ini (Sadikin \& Hamidah, 2020). Kemampuan menggunakan atau beradaptasi dengan teknologi sangat penting untuk dikuasai baik oleh pendidik maupun peserta didik (Almah dkk, 2020). Sehingga dengan berkembangnya ilmu pengetahuan dan teknologi yang akan terus berkembang, maka institusi pendidikan perlu mempersiapkan lulusan yang memiliki kompetensi untuk siap menghadapi segala bentuk tantangan dan perubahan.

National Education Assosiation (NEA) menyampaikan bahwa ada 4 kompetensi yang harus dikuasai peserta didik pada abad 21 dan dikenal dengan 4C (Communication, Collaboration, Critical Thinking and Problem Solving, Creative and Innovative) (National Education Assosiation, 2020). Namun, hadirnya revolusi industri 4.0, kompetensi tidak cukup dengan 4C, sehingga keterampilan abad 21 berubah menjadi 6C (Communication, Collaboration, Critical Thinking, Creative Thinking, Compassion, Computational Thinking). Dengan 2 tambahan kompetensi tersebut, diharapkan lulusan pelajar indonesia lebih cepat memahami perubahan teknologi yang ada di sekitar mereka (Cahdriyana \& Richardo, 2020).

Perubahan tuntutan output pendidikan menandakan bahwa pendidikan harus bersifat fleksibel, artinya perubahan dan perkembangan ilmu pengetahuan dan teknologi yang begitu cepat (tidak dapat diprediksi), maka dunia pendidikan sejatinya harus dapat menyesuaikan perubahan tersebut agar nantinya peserta didik mampu bertahan serta mampu beradaptasi dengan tantangan hidupnya. Jika dikaitkan dengan konteks suatu aliran filasat, maka progresivisme merupakan aliran yang sangat mendukung adanya pendidikan yang fleksibel, menghendaki suatu kemajuan yang akan membawa sebuah perubahan, bahkan menginginkan perubahan-perubahan secara cepat (Muhmidayeli, 2011; Mustaghfiroh, 2020). Media teknologi dalam pembelajaran yang terus berkembang, diiringi dengan tuntutan kompetensi dari 4C menuju 6C (relatif cepat berubah) menandakan bahwa progresivisme mewarnai pendidikan di era ini, terkhusus pendidikan dan pembelajaran dimasa pandemi Covid-19.

Mencermati penjelasan sebelumnya, maka artikel ini merupakan hasil penelitian kajian pustaka yang bertujuan untuk mendeskripsikan bagaimana pandangan filsafat progresivisme terhadap pembelajaran dimasa pandemi covid-19. Selain itu, pada bagian awal akan dibahas konsep filsafat progresivisme, bagaimana progresivisme memandang konsep belajar, kurikulum, guru dan sekolah. Selanjutnya yang terakhir akan lebih spesifik membahas posisi aliran progresivisme dalam konteks pembelajaran dimasa pandemi. 


\section{Metode}

Penelitian ini menggunakan jenis penelitian berupa studi kepustakaan (library research). Studi pustaka berkaitan dengan kajian teoritis berdasarkan data berupa catatan, buku, makalah atau artikel, jurnal dan referensi literatur ilmiah lainnya (Zed, 2004; Arikunto \& Jabar, 2010). Literatur ilmiah yang menjadi bahan kajian dalam penelitian ini berupa buku, jurnal serta artikel-artikel ilmiah yang terkait dengan topik yang dipilih. Data dikumpulkan dan dianalisis secara sekunder yang dikumpulkan yang bersumber dari buku maupun jurnal.. Sumber yang digunakan merupakan artikel yang terkait dengan tema yang akan dibahas terkait dengan filsafat progresivisme dan pembelajaran dimasa pandemi covid-19. Sedangkan analisis data dalam penelitian ini menggunakan metode analisis isi (content analysis).

\section{Hasil dan Pembahasan}

\subsection{Filsafat Progresivisme}

Aliran filsafat progresivisme lahir di Amerika Serikat sekitar tahun 1870 dan pembaharuan politik dinegara tersebut (Gutek, 1974). Pendidikan pada masa itu statis dan kaku, tidak fleksibel, tidak membentuk pribadi peserta didik yang aktif menjadi alasan para reformis (kaum progresivisme) menentang sistem pendidikan tradisional yang sangat kaku, menuntut disiplin ketat, dan membuat peserta didik menjadi pasif (Rukiyati \& Purwastuti, 2015). Progresivisme merupakan salah satu aliran filsafat pendidikan modern. Aliran filsafat ini diperkenalkan oleh William James (1842-1910) dan John Dewey (1859-1952) yang bermuara pada aliran filsafat pragmatisme melalui hubungan antara pendidikan progresif dengan filsafat pragmatisme (Sudarminta, 1994; Jalaluddin \& Idi, 2012; Fadlillah, 2017). Pragmatisme menyatakan bahwa realitas itu terus menerus berubah (Gutek, 1974). Sehingga pendidikan juga sejatinya harus berubah selaras dengan kemajuan dan perkembangan ilmu pengetahuan dan teknologi. Pola pikir progresivime sebagai filsafat pendidikan adalah kemajuan. Hal ini karena konsep kemajuan yang dapat menjadikan manusia terus aktif, kreatif, inovatif sehingga dapat memaksimalkan kecerdasannya untuk berpikir ilmiah guna menyelesaiakan permasalahan hidup dan tantangan zaman.

Jika ditinjau berlandaskan konsep ontologi, aksiologi dan epistimologi, maka secara ontologi progresivisme memiliki konsep bahwa tidak ada hal yang absolut. Tidak ada prinsip apriori atau hukum alam yang abstrak. Kenyataan adalah pengalaman transaksional yang selalu berubah. Dunia selalu berubah, dinamis. Hukum-hukum ilmiah hanya bersifat probabilitas, tidak absolut (Rukiyati \& Purwastuti, 2015). Secara Aksiologi, Progresivisme berpandangan bahwa nilai-nilai bukan suatu kualitas yang sudah tetap dalam dirinya melainkan individu atau masyarakat tersebut yang menentukan nilai-nilainya sendiri. Nilai yang bersifat relatif, timbul melalui bahasa dan pergaulan, keindahannya bergantung pada selera sosial, serta ukuran baik buruk berdasarkan kecocokan dengan hasil pengujian yang dialami manusia dalam pergaulan manusia (Rukiyati \& Purwastuti, 2015). Sedangkan secara epistimologi, progresivisme menyatakan bahwa pengetahuan dibentuk berdasarkan pengalaman dan akan terus 
berproses, berubah, dan disempurnakan. Sehingga interaksi antar manusia atau yang lainnya merupakan suatu keniscayaan untuk menghasilkan pengalaman yang akhirnya terbentuk pengetahuan. Selain itu, pengalaman juga dapat diperoleh atas upayanya untuk mencoba mengatasi dan menyelesaikan masalah-masalahnya yang muncul seiring dengan proses kehidupan itu sendiri (Rukiyati \& Purwastuti, 2015).

\subsection{Konsep Belajar Berdasarkan Pandangan Progresivisme}

Berdasarkan konsep epistimologi, bahwa pengetahuan itu dibentuk berdasarkan pengalaman melalui proses interaksi antar individu, sehingga hal ini menunjukkan bahwa belajar dalam pandangan progresivisme berarti membangun pengetahuan dan pengalaman melalui interaksi antar peserta didik. Hal ini sejalan dengan paham konstruktivime, anak harus didorong mengeksplorasi dunianya, untuk membangun suatu ilmu pengetahuan dan pemahaman (Santrock, 2004). John Lock berpandangan bahwa otak seorang anak ibarat botol kosong yang siap diisi dengan ilmu pengetahuan dan kebijaksanaan pendidik, dengan kata lain guru dianggap orang yang paling berpengetahuan sementara siswa pasif hanya siap menerimanya sebagaimana teori Tabularasa (Sentryo, 2019).

Ditinjau dari konteks kurikulum, progresivisme menghendaki bahwa mata pelajaran harus dibuat terintegrasi (tidak terpisah) (Anwar, 2015). Dengan kata lain, ilmu pengetahuan tidak hanya dipahami secara kognitif, tetapi juga dapat dipraktekkan (learning by doing), sehingga dapat dirasakan manfaatnya oleh masyarakat. Konsep ini tentunya sejalan dengan konteks pendidikan di Indonesia saat ini, seperti kebijakan pemerintah terkait program Merdeka Belajar Kampus Merdeka (MBKM) khususnya Perguruan Tinggi. Salah satu contoh dari program MBKM adalah program magang. Program magang yang dapat dilaksanakan hingga 2 semester diharapkan mampu memberikan pengalaman yang cukup kepada mahasiswa dengan pembelajaran langsung di tempat kerja (experiential learning). Belajar dalam konteks ini memberikan pengalaman yang baik karena langsung diaplikasikannya dalam kehidupan nyata, sehingga ketika lulus, mahasiswa akan lebih mantab dalam memasuki dunia kerja dan karirnya (Kemdikbud, 2020).

Dalam konteks sumber dan media pembelajaran, sumber belajar tidak terbatas dari buku cetak yang digunakan guru. Siswa dapat mengeksplorasi apapun untuk menjadi sumber belajarnya. Begitu terkait media pembelajaran, orang-orang progresif sangat peka terhadap kemajuan dan perkembangan, seperti teknologi informasi. Sehingga teknologi berupa multimedia misalnya, dapat dijadikan sebagai alat untuk membantu peserta didik dengan mudah memahami suatu materi dan mengkonstruksi pemahamannya (Madeali \& Prahani, 2018).

Dalam konteks metode pembelajaran, problem solving merupakan metode pembelajaran yang beraliran progresivisme. Hal ini karena Problem Solving memfasilitasi siswa memahami konsep suatu materi dan mengkonstruksinya menjadi ilmu pengetahuan (Rosidah, 2018), sebagaimana landasan epistimologi dari progresivisme itu sendiri. 


\subsection{Pendidik dan Peserta didik Berdasarkan Pandangan Progresivisme}

Secara epistimologi, progresif menghendaki bahwa peserta didiklah yang mengkonstruksi pengetahuan. Dengan kata lain, peserta didiklah yang harus aktif dalam proses pembelajaran, yang dikenal dengan pembelajaran berpusat pada siswa (student centre). Karena prinsip pembelajaran progresivisme menghendaki pembelajaran yang dipusatkan pada siswa (Fadlillah, 2017). Hal ini dikarenakan aliran progresif menganggap bahwa peserta didik telah memiliki kecerdasan, potensi kreatif, dinamis, sehingga mereka harus diberikan pengalaman menemukan, mengkonstruksi, serta memecahkan problem-problem hidupnya dan lingkungannya (Rukiyati \& Purwastuti, 2015).

Ketika peran peserta didik adalah aktif dalam pembelajaran, maka peran guru haruslah sebagai sebagai pembimbing, fasilitator yang mengarahkan dan memperkuat motivasi peserta didik dalam belajar. Guru dalam pandangan pendidikan progresif tidak sebagaimana guru pada umumnya seperti pembelajaran konvensional (Gutek, 1974). Sehingga guru juga perlu mengetahui bagaimana menjadi fasilitator yang baik, mengerti bagaimana memfasilitasi pembelajaran di kelas secara berkelompok agar masingmasing siswa dapat berpartisipasi dalam kelompoknya, memberikan lingkungan yang baik untuk belajar, serta bersikap demokratis dan adil dalam arti memperhatikan hakhak alamiah siswa secara keseluruhan (Gutek, 1974).

\subsection{Belajar di Era Pandemi dalam Perspektif Progresivisme}

Sejak wabah Covid-19 telah dinyatakan sebagai pandemi, pemerintah melalui Kementerian Pendidikan dan Kebudayaan memberikan arahan untuk melaksanakan proses pembelajaran di rumah dengan diterbitkannya Surat Edaran Kemdikbud Nomor 4 Tahun 2020 tentang Pelaksanaan Kebijakan Pendidikan dalam Masa Darurat Penyebaran Coronavirus Disease 19 (Covid-19). Salah satu isi edaran tersebut adalah pembelajaran yang sebelumnya dilaksanakan secara tatap muka, berubah menjadi sistem pembelajaran jarak jauh secara daring. Ada beberapa media yang dapat digunakan dalam pembelajaran daring pada umumnya, seperti aplikasi zoom, google classroom, webex meeting, google meet, whatapp dan lain sebagainya (Chandra \& Rustaman, 2009).

Peserta didik dan guru yang sebelumnya hanya terbiasa dengan pembelajaran konvensional, tatap muka secara langsung dituntut untuk berubah dan mengubah kebiasaan lama tersebut. Berubah disini dapat diartikan dipaksa untuk belajar beradaptasi dan belajar untuk memahami bagaimana menggunakan teknologi yang berkembang untuk digunakan sebagai sarana pembelajaran daring. Munculnya inovasi berupa platform pembelajaran daring serta pelaksana pembelajaran (khususnya guru) yang dituntut untuk beradaptasi dan berpikir inovatif bagaimana pembelajaran daring dapat terlaksana dengan baik, secara filosofi mengarah pada aliran progresivisme.

Progresivisme menginginkan perubahan, karena pendidikan harus berubah menyesuaikan dengan perkembangan ilmu pengetahuan dan teknologi (Chandra \& 
Rustaman, 2009). Dengan kondisi pandemi yang memaksa masing-masing individu untuk tidak berkumpul, menjaga jarak antar satu dengan lainnya, maka pembelajaran tatap muka harus dihindari. Sehingga sistem pembelajaran harus berubah, tidak bisa menggunakan cara lama. Perubahan sistem pembelajaran tatap muka ke pembelajaran daring, sejatinya memuat ajaran pada aliran progresivisme. Ditinjau dari sisi pendidik atau guru, adanya tuntutan untuk berpikir inovatif dalam mengembangkan materi, konten, strategi pembelajaran, hingga cara evaluasi yang dapat memaksimalkan pembelajaran daring agar berjalan lebih efektif.

Merujuk kembali pada Surat Edaran Kemdikbud Nomor 4 Tahun 2020 bahwa pelaksanaan pembelajaran daring/jarak jauh difokuskan pada pendidikan kecakapan hidup terkait covid-19 (Prabowo \& Dahlan, 2020). Kecakapan hidup ini dapat berupa mengetahui apa itu Covid-19, bagaimana penularannya, dan bagaimana pencegahannya dan lain sebagainya. Aliran progresif dapat memandang pembelajaran terkait kecakapan hidup dapat memberikan pengalaman secara nyata bagaimana covid merupakan sebuah masalah dalam kehidupan serta memahami bagaimana cara untuk mencegahnya. Bagaimana siswa memahami masalah dan mengetahui bagaimana cara penyelesaiannya adalah bagian dari pembelajaran problem solving yang merupakan metode pembelajaran berdasarkan aliran progresivisme (Rosidah, 2018).

Sejalan dengan aliran progresivisme tersebut, guru-guru matematika diharapkan mampu menjadikan kelas yang diampunya menjadi wahana yang konstruktif bagi peserta didik untuk menyiapkan berbagai kompetensi yang mendukung masa depannya tersebut (Sumaryanta \& Wibawa, 2020). Meskipun dalam suasana pandemi, pendidik tetap harus berusaha menfasilitasi siswa agar kemampuan berpikirnya dapat terus berkembang. Salah satunya adalah dengan memberikan pembelajaran berbasis project yang dikaitkan dalam kehidupan sehari hari (Richardo \& Martyanti, 2019 ; Richardo et al, 2021 ; Richardo \& Cahdriyana, 2021) Pada bagian akhir pembahasan, penulis akan memberikan contoh bagaimana guru dapat menyampaikan kompetensi suatu materi pembelajaran dengan mengaitkan pada kecakapan hidup terkait covid 19 pada pelajaran matematika melalui pembelajaran berbasis proyek. Pembelajaran ini akan berfokus pada proyek atau kegiatan sebagai tujuannnya. Melalui masalah yang diberikan kepada peserta didik, maka pembelajaran menjadi lebih bermakna. Hal ini dikarenakan peserta didik tidak hanya mengerti apa yang dipelajari melainkan menjadi tahu akan manfaat dari pembelajaran tersebut untuk lingkungan (Kosasih , 2014 ; Nurfitriyanti, 2016).

Dalam implementasinya, guru dapat memberikan pembelajaran berbasis project yaitu membuat cairan disinfektan. Disinfektan dapat dibuat dengan menggunakan campuran air dengan cairan seperti pembersih baju atau pembersih lantai. Dikaitkan dengan matematika, bahwa campuran tersebut dianalogikakan sebagai proporsi atau perbandingan banyaknya air dengan cairan pembersih. Sehingga melalui project ini siswa akan mempelajari konsep perbandingan baik pada bilangan bulat maupun pecahan. Dalam implementasinya, guru dapat memberikan sebuah permasalahan kepada siswa untuk diselesaikan melalui pembuatan diinfektan dalam mempelajari konsep perbandingan. Siswa diberikan sebuah lembar kerja untuk dengan beberapa 
pertanyaan, misalnya "Buatlah cairan disinfektan serta jawablah pertanyaan berikut (a) Berapakah perbandingan banyaknya air dan cairan pembersih baju (Bacylin) untuk membuat cairan disinfketan dalam ukuran mili liter (ml)? ; (b) berapa mili liter (ml) perbandingan antara air dan Bacylin untuk membuat disinfektan dirumahmu? Serta berapa mili liter cairan disinfektan yang telah kamu buat?

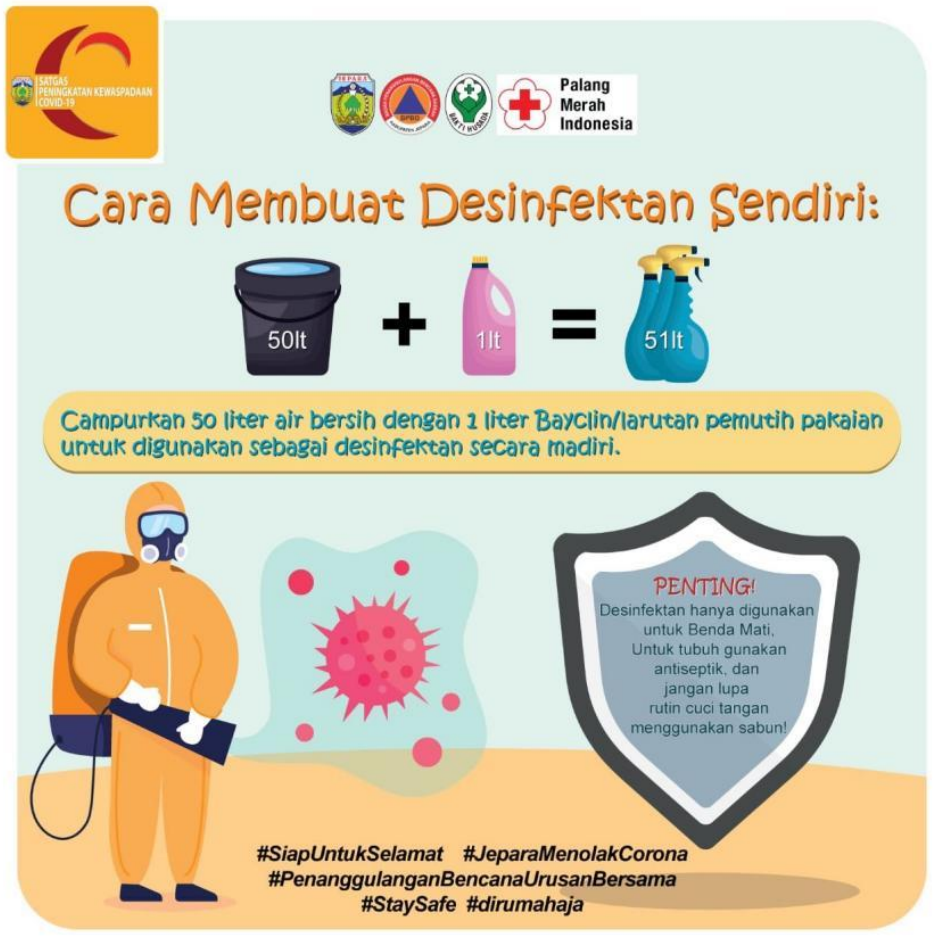

Gambar 1. Cara Membuat Disinfektan

Sumber : https://pbs.twimg.com/media/ETdd8bFUYAEwCyl.jpg:large

Berdasarkan Gambar 1, Siswa telah dapat memperoleh informasi untuk menjawab pertanyaan (a). Serta dalam hal ini, siswa juga diajarkan untuk mencari sumber-sumber belajar melalui teknologi dan internet.. Untuk menjawab soal (a) Siswa akan menggunakan konsep satuan volume. sehingga jika perbadingan bacylin dengan air adalah 1 : 50 dalam satuan liter untuk mendapatkan 51 liter cairan disinfektan, maka dalam satuan mili liter perbandingannya adalah 1000:5000. Demikian juga untuk pertanyaan (b), masing-masing siswa akan membuat diisfektan dengan ukuran yana berbeda, tergantung dari banyaknya cairan bayclin yang dimilikinya. Jika siswa memiliki 100 mili liter bayclin, maka yang dibutuhkan adalah 500 mili liter air untuk membuat cairan disinfektan. Sehingga cairan disinfektan yang telah dibuat sebanyak 600 mili liter.

Melalui pembelajaran berbasis proyek tersebut siswa tidak hanya melatih kemampuan berpikir matematisnya melalui soal-soal berbasis masalah, namun siswa juga belajar mengetahui bagaimana cara siswa mengetahui bahwa covid merupakan masalah dalam kehidupan, serta memahami bagaimana cara pencegahan dengan membuat disinfektan. Inilah yang dimaksud dengan pemahaman kecakapan hidup terkait covid 19. 


\section{Kesimpulan}

Pembelajaran dimasa pandemi mengarahkan sektor pendidikan, terutama sistem pembelajaran untuk melakukan perubahan menuju pada pembelajaran berbasis teknologi dalam jaringan. Guru diharapkan dapat berinovasi mengembangkan konten dan strategi yang baik dengan sistem pembelajaran ini. Disinilah peran aliran progresivisme sebagai filsafat pendidikan dalam mewarnai pendidikan khususnya pembelajaran di era pandemi yang tidak hanya di Indonesia melainkan di negara-negara lain di dunia.

\section{Daftar Pustaka}

Almah, U., Thohari, M. I., \& Lismanda, Y. F. (2020). Pemanfaatan teknologi pembelajaran pendidikan agama islam di tengah masa pandemi covid-19 berbasis social distancing di smkn 5 Malang. Vicratina: Jurnal Pendidikan Islam, 5(10), 134-142.

Anwar, M. (2015). Filsafat pendidikan. Kencana : Jakarta

Arikunto, S., \& Jabar, C. S. A. (2010). Evaluasi Program Pendidikan. Jakarta: Bumi Aksara

Cahdriyana, R. A., \& Richardo, R. (2020). Berpikir Komputasi Dalam Pembelajaran Matematika. LITERASI (Jurnal Ilmu Pendidikan), 11(1), 50-56.

Chandra, D. T., \& Rustaman, N. (2009). Perkembangan Pendidikan Teknologi Sebagai Suatu Inovasi Pembelajaran Pada Pendidikan Dasar di Indonesia. Jurnal Pengajaran MIPA, 14(2), 37-50.

Fadlillah, M. (2017). Aliran Progresivisme dalam Pendidikan di Indonesia. Jurnal Dimensi Pendidikan dan Pembelajaran, 5(1), 17-24.

Gutek, G.L. 1974. Philosophical and Ideological Perspectives on Education. Prentice-hall. inc : USA

Jalaluddin \& Idi, A. (2012). Filsafat Pendidikan; Manusia, Filsafat dan Pendidikan. Jakarta: Rajawali Press.

Kemdikbud RI. (2020). Buku Panduan Merdeka Belajar Kampus Merdeka. Direktorat Jendral Pendidikan Tinggi : Jakarta

Kosasih. (2014). Strategi Belajar Dan Pembelajaran. Bandung: Yarma Widya

Madeali, H., \& Prahani, B. K. (2018). Development of multimedia learning based inquiry on vibration and wave material. In Journal Physics: Conference Series (Vol. 997, No. 1, p. 012029).

Marbun, P. (2020). Disain pembelajaran online pada era dan pasca covid-19. CSRID (Computer Science Research and Its Development Journal), 12(2), 129-142.

Muhmidayeli, M. (2011). Filsafat Pendidikan. Bandung: Refika Aditama

Mustaghfiroh, S. (2020). Konsep “Merdeka Belajar” Perspektif Aliran Progresivisme John Dewey. Jurnal Studi Guru Dan Pembelajaran, 3(1), 141-147.

National Education Association. (n.d.). Preparing 21st Century Students for a Global Society: An Educator's Guide to the "Four Cs." Diakses 20 Desember 2020 dari http://www.nea.org/assets/docs/A-Guide-to-Four-Cs.pdf.

Nurfitriyanti, M. (2016). Model Pembelajaran Project Based Learning Terhadap Kemampuan Pemecahan Masalah Matematika. Formatif: Jurnal Ilmiah Pendidikan MIPA, 6(2).

Prabowo, A., \& Dahlan, J. A. (2020). Pengembangan Tes Matematika dengan Konteks COVID-19 untuk Siswa SMP/MTs Kelas VIII. Jurnal Elemen, 6(2), 302-317.

Richardo, R., \& Martyanti, A. (2019). Developing ethnomathematical tasks in the context of yogyakarta to measure critical thinking ability. In Journal of Physics: Conference Series (Vol. 1188, No. 1, p. 012063). IOP Publishing.

Richardo, R., et.al. (2021). Pendampingan Guru-Guru SD Krapyak Wetan dalam Menerapkan Pembelajaran Tematik dengan Pendekatan STEM. JPM Ournal Pemberdayaan Masyarakat), 6(1).

Richardo, R., \& Cahdriyana, R. A. (2021). Strategi meminimalkan beban kognitif eksternal dalam pembelajaran matematika berdasarkan load cognitive theory. Humanika, Kajian Ilmiah Mata Kuliah Umum, 21(1), 17-32. 
Rosidah, A. (2018). The Use Of Problem Solving Learning Method To Improve Students'Critical Thinking. In Sepeda (Seminar Pendidikan Dasar) PGSD FKIP Unpas (Vol. 1, No. 1, pp. 289-301).

Rukiyati, P., \& Purwastuti, L. A. (2015). Mengenal filsafat pendidikan. Fakultas Ilmu Pendidikan Universitas Negeri Yogyakarta. Diakses online : http://staffnew.uny.ac.id/upload/131763780/pendidikan/bpk-mengenal-filsafatpendidikan.pdf

Sadikin, A., \& Hamidah, A. (2020). Pembelajaran Daring di Tengah Wabah Covid-19:(Online Learning in the Middle of the Covid-19 Pandemic). Biodik, 6(2), 214-224.

Santrock. (2004). Psikologi Pendidikan. Jakarta: Kencana Prenada Media Grup.

Sentryo, I. (2019). Penerapan Model Pembelajaran Kooperatif Tipe Team Assisted Individualization (TAI) Untuk Meningkatkan Hasil Belajar Siswa Pada Materi FPB Dan KPK Di Kelas V SD egeri 10 KabangkJurnal Ilmiah Pembelajaran Sekolah Dasar (JIPSDa. ), 1(1).

Sudarminta. (1994). Filsafat Pendidikan. Yogyakarta: Universitas Sanata Dharma.

Sumantyo, F. D. S. (2020). Pendidikan Tinggi di Masa dan Pasca Covid-19. Jurnal Kajian Ilmiah, 1(1), 81-92.

Sumaryanta, S., \& Wibawa, A. (2020). REKONSTRUKSI PEMBELAJARAN MATEMATIKA DI ERA REVOLUSI INDUSTRI 4.0. IDEAL MATHEDU: Indonesian Digital Journal of Mathematics and Education, 7(1), 11-25. Retrieved from http://p4tkmatematika.kemdikbud.go.id/journals/index.php/idealmathedu/article/view/ 135

Zed, M. (2004). Metode Penelitian Kepustakaan. Jakarta: Yayasan Obor Indonesia. 